\title{
ENTRE A GENIALIDADE E A JUSTIÇA: A Trajetória do Escritor Naturalista Émile Zola ${ }^{1}$ \\ BETWEEN THE GENIUS AND THE JUSTICE: The Trajectory of the Naturalist Writer Émile Zola
}

Rodrigo Carvalho*

\begin{abstract}
Resumo
Émile Zola firmou-se como um marco na literatura com sua tentativa de aproximar a arte do saber científico vigente, conforme os preceitos de seus romances experimentais ou romances de tese. Além disso, a repercussão do autor, sobretudo no mundo ocidental, não se restringiu somente às suas obras: seu destaque se revela no elevado engajamento político como figura libertária.
\end{abstract}

Palavras-chave: Émile Zola (1840-1902), naturalismo, biografia.

\section{Abstract}

Émile Zola has established as a landmark in the literature with his attempt to approching the art to the current scientific knowledge, according to his precepts of experimental novels or novels thesis. Moreover, the impact of the author, especially in the western world, was not restricted only to his works: his importance is revealed too in his high political commitment as a libertarian figure.

Keywords: Émile Zola (1840-1902), naturalism, biography.

O nome de Zola não costuma figurar nas discussões sobre os problemas do romance moderno; e certos críticos de vanguarda chegam a afirmar que "Zola já não é lido". A afirmação não corresponde à verdade. Zola continua lido. Mas, em numerosas edições e traduções baratas, a sua obra está circulando pelo mundo inteiro, constituindo para inúmeros leitores a primeira iniciação e a iniciação definitiva na literatura. 0 método de Zola deixa entrar luz em lugares escondidos. Não há nada de "misterioso" na sua obra nem na sua personalidade de um pequeno-burguês tímido e ambicioso, trabalhador assíduo, escritor profissional com desejos confessados de fazer publicidade e ganhar dinheiro. Zola tem muito de jornalista, de repórter; e, na qualidade de repórter, descobriu o mundo moderno, ao qual, até então, a literatura não prestara a atenção devida. ${ }^{2}$

Émile Zola não foi o único a denunciar uma realidade bastante assustadora e impactante, contudo destacou-se em suas contribuições por seu estilo de expressão autodenominado naturalista. ${ }^{3}$ Émile-Édouard-Charles-Antoine Zola nasceu em 2 de abril de 1840 em Paris. Filho de

\footnotetext{
1 Este trabalho compõe uma parcela das informações apresentadas em minha monografia de conclusão de curso - Estética naturalista como expressão da sociedade industrial: uma leitura da obra Germinal de Émile Zola, sob orientação da Profa. Dra. Josianne Francia Cerasoli.

Bacharel e Licenciado em História pela Universidade Federal de Uberlândia - MG. Pós-Graduando em Gestão e Políticas Públicas. Integrante do NEPHISPO - Núcleo de Estudos e Pesquisas em História Política. Contato: rudrigu7@gmail.com.

2 CARPEAUX, Otto Maria. História da literatura ocidental. Rio de Janeiro: O Cruzeiro, 1966 apud ZOLA, Émile. Germinal. Tradução de Francisco Bittencourt. São Paulo: Martin Claret, 2007, p. 448.

3 As informações biográficas presentes nesta análise foram baseadas na coleção Os Imortais da Literatura Universal (1979) e nos estudos de Henri Mitterand (1986 e 2006) - professor emérito da Sorbonne Nouvelle (Paris). 0 título foi inspirado nestes mesmos estudos; a noção de justiça atrelada à função social do literato, sobretudo como gênio romântico, permeia os diversos estudos sobre Zola. Cf. MITTERAND, Henri. Émile Zola - entre a genialidade e a justiça. In: Históriaviva, ed. 35, set. 2006. Disponível em <http://www2.uol.com.br/historiaviva/reportagens/emile_zola-
} 
um engenheiro de origem veneziana, Francesco Zola, e de Émilie-Aurélie Aubert, 24 anos mais jovem que o marido. Zola veio a falecer naquela mesma cidade em 29 de setembro de 1902. É considerado tanto uma referência libertária em seu país, como um dos escritores de maior expressão da sociedade francesa e idealizador da estética naturalista no campo literário, ao levar a descrição realista aos extremos da crueza e denúncia dos "lados podres" do homem.

Órfão de pai aos sete anos, Zola passou a infância em Aix-en-Provence. Aos 18 anos retornou à Paris para estudar. Diante de complicações financeiras familiares foi levado a trabalhar em diversos escritórios em cargos pouco influentes. Iniciou sua carreira jornalística publicando colunas no Cartier de Villemessant's e no Controversial. Naquela época, seus textos eram permeados de críticas ao governo de Napoleão III e à Igreja.

Uma recomendação o fez ingressar na Librairie Hachette em março de 1862, famosa editora francesa. Agarrou com todas as forças a chance que passava. Atendia ao mesmo tempo editores, escritores e jornalistas, o que the permitiu organizar rapidamente uma valiosa agenda de contatos. Educou-se como livre-pensador na leitura de autores da Hachette e de outras editoras, tornando-se um crítico literário, cronista e crítico de arte aos 25 anos. Admirava os artistas que desafiavam o conformismo: os Goncourt, Flaubert, Courbet, Manet. ${ }^{4}$

\footnotetext{
_entre_a_genialidade_e_a_justica.html >. Acesso em 31 out. 2009; Zola et naturalisme. Paris: P.U.F. (Collection Que sans-je?), 1986; OS IMORTAIS DA LITERATURA UNIVERSAL, Abril S/A Cultural e Industrial, 1979.

$4 \quad$ MITTERAND, op. cit., 2006, p. 2. Edmond Louis Antoine Huot de Goncourt (1822-1896) e Jules de Goncourt (1830-1870) foram escritores, críticos e editores franceses. O primeiro ficou conhecido pelo Prêmio Goncourt - o prêmio literário mais cobiçado na França entre as produções em prosa. Gustave Flaubert (1821-1880) foi um escritor francês destacado por suas análises psicológicas sobre o comportamento social. Madame Bovary (1857) e L'Éducation sentimentale (1869) estão entre suas principais obras. Gustave Courbet (1819-1877) foi um pintor realista francês. Édouard Manet (1832-1883) foi um pintor e artista gráfico francês.
} 


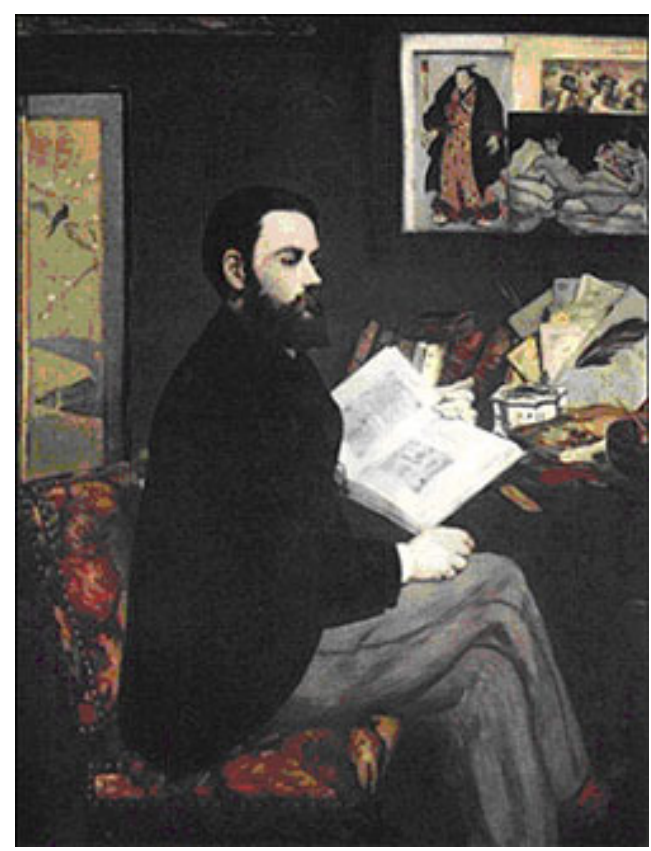

Figura 1. Zola retratado pelo amigo Manet, 1868. Óleo sobre tela, $146 \mathrm{~cm} \times 114 \mathrm{~cm} .^{5}$

Em 1866, após sua saída da Hachette, seguiram-se anos difíceis. Vivia exclusivamente de sua pena passando por diversos jornais pequenos ou produzindo um romance por ano. Os pagamentos por sua escrita não davam retorno suficiente. Paradoxalmente, foi o Império que o livrou das dificuldades. Em maio de 1868, Napoleão III liberalizou o regime de imprensa e os jornais oposicionistas surgiram com força. Zola ingressou no La Tribune e por meio de amigos de Victor Hugo teve colunas no Rappel. A propaganda democrática o alimentava e com Paris atacada pelo exército prussiano (1870-1871) embarcou para Marselha, onde fundou o jornal La Marseillaise. Posteriormente, em Bordeaux trabalhou como cronista no La Cloche.

Zola arquitetou minuciosamente a construção de seu edifício literário; buscou um sistema filosófico e uma visão de mundo que retratasse seu tempo. Não encontrou somente uma filosofia, porém uma fórmula para seu ideário. Naturalismo foi a palavra que designou sua nova literatura. Fomentou uma "literatura científica" graças a todo o movimento de doutrinas cientificistas e materialistas que proliferaram ao longo do século XIX. Mostrou-se em sintonia com autores em

$5 \quad$ Fonte: Acervo Museu d'Orsay (Paris). Disponível em: <http://www.musee-orsay.fr/en/collections/works-infocus/painting.html?no_cache=1\&zoom=1\&tx_damzoom_pi1[showUid]=2281>. Acesso em 31 out. 2009. Émile Zola escreveu um artigo declarando que Édouard Manet seria um dos mestres do futuro, defendendo-o de acusações que lhe faziam. Agradecido, Manet pintou o retrato do escritor. 0 quadro foi feito no estúdio do pintor e o cenário montado de acordo com a personalidade do retratado. 
ascensão como Charles Darwin e sua teoria evolucionista, Honoré de Balzac e sua ampla obra literária, bem como as doutrinas socialistas que começavam a se arregimentar. ${ }^{6}$

Foi especificamente a partir de uma adaptação das noções elaboradas pelo médico Claude Bernard, em Introdução ao Estudo da Medicina Experimental (1865), que o escritor chegou ao seu método de romance experimental, decidindo-se que seus romances deveriam ter rigor científico. ${ }^{7}$ Segundo Bernard, a medicina, que até então era considerada uma arte, poderia se transformar numa verdadeira ciência se adotasse 0 método de experimentação, já praticado pelas chamadas "ciências duras", isto é, a física e a química. ${ }^{8}$

Nesse sentido, Zola indica que o observador é aquele que aplica os métodos de investigação dos fenômenos sem variar as condições de existência destes; já o experimentador emprega métodos de investigação fazendo variar as condições, de modo a fazer os fenômenos aparecerem em circunstâncias diferentes.

[...] o observador apresenta os fatos tal qual os observou, define o ponto de partida, estabelece o terreno sólido no qual as personagens vão andar e os fenômenos se desenvolver. Depois, o experimentador surge e institui a experiência, quer dizer, faz as personagens evoluírem numa história particular, para mostrar que a sucessão dos fatos será tal qual a exige o determinismo dos fenômenos estudados. Trata-se quase sempre de uma experiência "para ver", como a designa Claude Bernard. O romancista sai em busca de uma verdade. ${ }^{9}$

Dessa forma, a conduta humana para Zola é determinada pela herança genética, pela fisiologia das paixões e pelo ambiente. Afirmou em 0 Romance Experimental (1880) que 0 desenvolvimento das personagens e enredos deve ser determinado sobre aspectos científicos similares aos empregados em experiências de laboratório. Assim, procurou empregar o método

$6 \quad$ Charles Robert Darwin (1809-1882) foi um naturalista britânico conhecido por suas teorias evolucionistas e pela seleção natural e sexual. Honoré de Balzac (1799-1850) foi um romancista francês. La comédie humaine, que conta com oitenta e oito escritos, é considerada sua obra-prima.

$7 \quad$ Claude Bernard (1813-1878) foi um médico francês. A Universidade de Lyon ostenta o seu nome como Université Claude Bernard Lyon I.

$8 \quad$ ZOLA, Émile. O romance experimental e o naturalismo no teatro. São Paulo: Perspectiva, 1982, p. 41.

$9 \quad$ Idem, p. 31. Prossegue o escritor em Do Romance, outra obra em que teoriza sobre seu método: "Conforme escrevi, para grande escândalo dos meus colegas, a imaginação já não representa aí um papel dominante; torna-se dedução, intuição, age sobre os fatos prováveis que pôde observar diretamente e sobre as consequências possíveis dos fatos que se trata de estabelecer logicamente segundo o método". ZOLA, Émile. Do romance. Tradução de Plínio Augusto Coelho. São Paulo: Edusp, 1995, p. 36. 
científico vigente à época fundamentado em conceitos como a hereditariedade e o determinismo científico. ${ }^{10}$

Zola acreditava que sua escrita representava as cores verdadeiras e tristes que pintavam a classe operária sem elos publicitários e/ou políticos. Dizia que estudava os temperamentos e não os caracteres, tendo como preferência, personagens dominados pelo sentimento de revolta. Tais noções nortearam seu estilo naturalista de expressão, permeando grande parte de suas obras. 0 que Bernard havia feito com o corpo humano, Zola procurou fazer com as paixões e os meios sociais.

\begin{abstract}
Com o romance naturalista, o romance de observação e de análise, as condições mudam imediatamente. 0 romancista inventa ainda mais; inventa um plano, um drama; apenas é a ponta do drama, a primeira história surgida; e que a vida cotidiana sempre lhe fornece. Em seguida, na estruturação da obra, isso tem bem pouca importância. Os fatos só estão lá como desenvolvimentos lógicos das personagens. 0 grande negócio é colocar em pé criaturas vivas, representando diante dos leitores a comédia humana com a maior naturalidade possivel. Todos os esforços do escritor tendem a ocultar o imaginário sob o real. ${ }^{11}$ (grifo nosso)
\end{abstract}

As primeiras obras Contes a Ninon (1864) e o romance La Confession de Claude (1865) marcaram sua transição para o naturalismo, segundo seus críticos e estudiosos, visivelmente presente em Thérèse Raquin (1867). Em 1871 começou a trabalhar num ciclo de vinte romances, Les Rougon-Macquart, que tinha como subtítulo História Natural e Social de uma Família no Segundo Império. A década de 1870 foi permeada com uma ilimitada fé na ciência e no progresso e parecia propiciar uma tarefa desta envergadura. Zola buscou apresentar uma abordagem inovadora inspirada nos estudos da época ao retratar a decadência social de seu tempo. Com a proposta de não escrever um simples romance, este ciclo de obras valeria como uma análise científica pormenorizada do homem e da moral.

10 Foi em diversas teorias médicas do século XIX sobre a hereditariedade que Émile Zola pôde encontrar caminhos possíveis para sua literatura. Ele leu a obra de Moreau de Tours, Da identidade do estado do sonho e da loucura (1855), o Tratado das degenerescências de Auguste Morel (1857) e a Fisiologia das Paixões de Charles Letourneau (1868). Entre os dossiês preparatórios que organizava antes de começar a escrever, há anotações sobre a Hereditariedade nas doenças do sistema nervoso (1886) de Jules Déjerine, assim como sobre Ensaios sobre a hereditariedade e a seleção natural de Weismann. Mas foi sobretudo o Tratado filosófico e fisiológico da hereditariedade natural (dois volumes, 1847 e 1850), do médico Prosper Lucas, a obra sobre o tema que mais impressionou Zola, a ponto de utilizá-la praticamente como fio condutor para sua saga familiar - os 20 livros de Os Rougon-Macquart, publicados entre 1871 e 1893. RODRIGUES, Marília Mezzomo. "Sou um historiador e não um fornecedor de imundícies!" - medicina experimental e hereditariedade no naturalismo de Émile Zola. In: Revista de História Regional, n. 14 (2), Inverno, 2009, p. 34-35.

$11 \quad$ ZOLA, op. cit., 1995, p. 24. 
Tantos mundos e condutas observados e compreendidos em sua violenta verdade. Um acerto de contas libertário com as hipocrisias bem-pensantes; uma expansão contínua da sátira e da ironia. Uma montagem exagerada, excessiva, no estilo de Flaubert. É assim a crônica monumental dos Rougon-Macquart, na qual com frequência o sexo e a morte fazem par e onde se encontram a cada instante estranhezas mais surrealistas que "naturalistas". ${ }^{12}$ (grifo nosso)

A saga de Les Rougon-Macquart, finalizada em 1893 e inspirada em A Comédia Humana de Honoré de Balzac, sanaria os problemas financeiros do escritor. A intenção era aproximar este ciclo de romances com os ideais da ciência de seu tempo, como os preceitos deterministas de Hippolyte Taine, a filosofia positivista de Auguste Comte ${ }^{13}$, a prática experimental de Bernard e os princípios da hereditariedade e a teoria da evolução de Darwin. Aproximando-se do interesse sociológico e voltando-se para a obra de Balzac, todavia diferentemente deste, Zola concebeu o plano de sua série a priori, enquanto o autor de A Comédia Humana havia organizado seu conjunto com esta designação após um certo número de escritos. Além disso, enquanto Balzac centrava suas obras em certa medida numa análise econômica, Zola pendia para as ciências naturais e a sociologia positivista retratando não somente aspectos econômicos, bem como seus resultados sociais perante o intenso desenvolvimento industrial. ${ }^{14}$

O ciclo dos Rougon-Macquart vai expor ficcionalmente a formação da hegemonia capitalista numa sociedade de economia ainda tradicional e rural, já diferenciada pelo próprio avanço da produção capitalista, entre crises mundiais da agricultura, do comércio, da indústria, e num Império fragilizado. 0 progresso vai cavando 0 abismo entre 0 operário e o burguês, que Napoleão III tentou amenizar com medidas liberais entre 1864 e 1870. A lembrança da Comuna de Paris acompanhará a organização crescente do proletariado em tempos de fortalecimento do capital. Tomando o ciclo dos RougonMacquart como conjunto, nele a divisão do trabalho, da vida social e das classes estão expostas pela sua própria separação em cada um dos romances que o compõem, todavia ligados pelos mesmos fundamentos modernos. Desse modo Zola apreendia, como um problema, a totalidade fragmentada do mundo do capital. E sua narrativa alcança um máximo rendimento ficcional porque tem, como referência, a herança mais radical do

12 MITTERAND, op. cit., 2006, p. 3.

13 Hippolyte Adolphe Taine (1828-1893) foi um filósofo e historiador francês comumente identificado como positivista. Caro a Zola, crítico literário, professor e escritor; seguiu os cursos no Museu e Academia de Medicina em Paris. Em sua tese de doutorado, Estudo sobre as fábulas de La Fontaine (1853), aplicou pela primeira vez as premissas de seu método crítico, que entende todo escritor por sua "faculdade mestra", própria a cada artista, determinada por três fatores: o meio, o momento e a raça. Interessado pela possibilidade de se explicar as obras pelos fatos históricos e fisiológicos e explicar o indivíduo por sua época e seu meio, Zola admirava a "exatidão da ciência" do método de Taine, mas não 0 aceitava completamente, por acreditar que nele a personalidade do artista não recebia a importância que merecia. RODRIGUES, op. cit., p. 36-37. Auguste Marie François Comte (1798-1857) foi um filósofo francês, cujas idéias e preposições foram amplamente debatidas.

$14 \quad$ SILVA, Júlio Cezar Bastoni da. O cortiço e os limites do romance experimental. Monografia (Graduação) Curso de Letras, Universidade Federal de São Carlos, 2009, p. 10. 
romance anterior, respondendo dessa maneira ao desafio formal de apresentar criticamente a totalidade da experiência do seu tempo. ${ }^{15}$ (grifo nosso)

Zola terminou por conquistar fortuna e se instalou em Paris. Frequentava os salões de alguns amigos mais próximos como o editor Charpentier, os Manet e Flaubert. Em 1878, comprou uma casa de campo em Médan. Todavia, a riqueza e o sucesso não o tornaram feliz. A morte da mãe, e de seu amigo Flaubert, conduziram-no à beira da depressão.

Entre 1876 e 1884 ocorre a explosão do Naturalismo como movimento. Zola é levado à condição de "chefe" após um jantar oferecido por jovens escritores àqueles considerados seus mestres: Flaubert, os Goncourt e Zola. O jantar, em abril de 1877, entrou para a história literária como o momento da oficialização do movimento naturalista. Nesse período foi publicado L'Assommoir (1877), romance que consagrou Zola e possibilitou-lhe a aquisição de uma casa em Médan, onde reuniam-se com frequência os escritores mencionados. Destas reuniões regulares surgiu Les Soires de Médan [...] Em 1880, Zola assombra o meio literário vendendo, no dia do lançamento, 55 mil volumes de Nana. Foi a época do crescimento constante do mercado editorial. ${ }^{16}$

Ao combinar teorias polêmicas como o darwinismo, o evolucionismo e o determinismo científico, Zola inovou com sua escrita conhecida como romance de tese. 0 estilo ou estética naturalista foi uma ramificação radical do realismo. Na literatura, os escritores realistas desejavam retratar o homem em sua totalidade com base nas teorias científicas vigentes em seu tempo. Em contraposição ao romantismo, que esbanjava a face sonhadora e idealizada da vida, os realistas acreditavam na necessidade de se retratar o cotidiano massacrante, o egoísmo, a miséria e a impotência humana. ${ }^{17} \mathrm{~A}$ origem do naturalismo se confunde e depende da origem do realismo, linha de frente contra a estética romântica.

15 CARA, Salete de Almeida. Marx, Zola e a Prosa Realista. São Paulo: Ateliê Editorial, 2009, p. 13-14.

16 SILVA, Eduardo César Ferreira da. A obra de Émile Zola no Brasil: notas para um estudo de recepção crítica. Dissertação (Mestrado em Literatura), Universidade Federal de Santa Catarina, 1999, p. 3. Zola assume a chefia do movimento, não por vaidade ou por ignorância como ele atesta que seus detratores o acusaram, mas por importância dentro desse movimento, seja na teorização do método, ou na prática, com o grupo literário das soirées de Médan. SILVA, op. cit., 2009, p. 50.

$17 \quad$ Gustave Flaubert, Honoré de Balzac, Charles Dickens, Eça de Queirós, Júlio Ribeiro e Aluízio de Azevedo foram alguns dos expoentes da escrita realista. Émile Zola é considerado o idealizador do naturalismo e o escritor que mais se identificou com esta corrente literária. Assim escreve Zola, em carta a Antony Valabrègue, em 18 ago. 1864, a respeito de sua nova estética fundamentando-se na ideia de teoria da tela. "Vemos a criação dentro de uma obra, através de um homem, através de um temperamento, uma personalidade. A imagem que se produz sobre esta tela de nova espécie é a reprodução das coisas e das pessoas colocadas para além, e esta reprodução, que não saberá ser fiel, mudará o tanto de vezes que uma nova tela venha a se interpor entre nosso olho e a criação... A tela clássica é, em última palavra, uma lente de aumento que desenvolve as linhas e fixa as cores de passagem... A tela romântica é, em suma, um prisma, de refração patente, que parte todo raio luminoso e o decompõe em um espectro solar ofuscante... $A$ tela realista é um simples óculos de leitura, muito fino, muito claro e que tem a pretensão de ser tão perfeitamente transparente que as imagens the atravessam e se reproduzem em seguida em toda sua realidade... Todas as minhas 
A escola naturalista inicia-se na segunda metade do século XIX com a conjugação de fatores recorrentes do industrialismo, isto é, as contradições sociais e o desenvolvimento das ciências. O naturalismo surge num momento de grandes transformações sociais, econômicas, políticas e tecnológicas no continente europeu. Os escritores naturalistas buscavam retratar a realidade aprofundando-a em suas mazelas sociais como os vícios, as paixões, os sentimentos humanos mais torpes e animalescos, considerados baixos e sujos, sendo este um recorte social em termos gerais da vida burguesa e proletária.

\begin{abstract}
Coexistindo com as outras concepções filosóficas, políticas, econômicas e artísticas do século XIX, o ideário cientista também passou a ser uma possibilidade para lidar e explicar as mudanças naturais e sociais; todas as questões poderiam (e deveriam) ser respondidas de modo científico. Pode-se dizer que as concepções de organismo social e devir histórico, além da vontade de se produzir conhecimento objetivo, se encontraram nas principais obras da segunda metade do século 19. Se Darwin apresentou as evidências científicas da evolução, indo além das enunciações e especulações que já existiam sobre o tema, percebe-se, por exemplo, que Comte buscou sintetizar uma ciência da sociedade; Renan, a ciência da religião; Marx concebeu seu socialismo como científico; Stuart Mill concebia a ciência da natureza humana; Émile Zola, o grande nome do naturalismo literário, imaginou uma literatura unida à ciência, inspirando-se nas formulações do fisiologista Claude Bernand que, por sua vez, entendia que a medicina deveria deixar de ser a "arte de curar" e estabelecer um corpus científico, a medicina experimental..$^{18}$ (grifo nosso)
\end{abstract}

Para os autores naturalistas, o meio físico condicionava os acontecimentos, onde as personagens seriam resultado de sua ascendência e das condições que conviviam. Nesta concepção, o ambiente refletia a humanidade e se este era triste e sujo, assim deveriam ser seus habitantes. Percebemos a força que ideias diversas e provenientes das ciências biológicas e sociais do século XIX tiveram nas explicações naturalistas sobre os fenômenos da vida e do comportamento humano.

\footnotetext{
0 realismo se tingirá de naturalismo, no romance e no conto, sempre que fizer personagens e enredos submeterem-se ao destino cego das "leis naturais", que a ciência da época julgava ter codificado [...] é uma grande mancha pardacenta que se alonga aos nossos olhos: cinza como o cotidiano do homem burguês, cinza como a eterna repetição de mecanismos de seu comportamento, cinza como a vida das cidades que já então se unificava em todo o Ocidente. ${ }^{19}$ (grifo nosso)
}

simpatias, se é necessário dizer, são pela tela realista; ela comenta minha razão e eu sinto nela imensas belezas de consistência e verdade". ZOLA, 1864 apud RODRIGUES, op. cit., p. 38-39.

18 RODRIGUES, op. cit., p. 33.

19 BOSI, Alfredo. História concisa da literatura brasileira. São Paulo: Cultrix, 1976, p. 168. Conforme Hauser, o escritor naturalista descobre na realidade um certo traço, uma certa tendência a que se gostaria de dar mais ênfase, que se gostaria de promover ou de combater. O naturalismo não tem por alvo a realidade como um todo, não a "natureza" ou 
A consciência de uma crise social instalada durante o século XIX guiou a busca de soluções para os problemas da sociedade. A literatura, não alheia às incongruências de seu tempo, retratava intenções de reforma, como é o caso de Zola. Este, munido de uma base científica, permeada principalmente pelas ciências naturais, teorizou métodos de composição do romancista naturalista, sobretudo em duas obras críticas Do Romance e 0 romance experimental. Nestas obras o autor apresenta toda sua crença em uma concepção artística desprovida de qualquer indulgência com relação à raça humana e influenciada pelas descobertas científicas e pelo positivismo.

Para Ítalo Caroni, a crença de Zola chega a contornos de uma verdadeira utopia. Na base de seu pensamento estava o enfoque negativo da condição humana e sua dimensão natural; 0 homem condicionado pelo meio físico e pelo estigma hereditário. "Como a pedra e a planta, o ser humano tem o seu destino inscrito no cosmos universal, e não escrito numa bíblia qualquer". $E$, "como um espírito autêntico de seu tempo, Zola procurou introduzir, nessa visão naturalista, a esperança moderna no milagre científico". Conforme Caroni, com ingenuidade, acreditava-se então no poder do progresso científico como a regeneração da espécie humana. ${ }^{20}$

\footnotetext{
Não somos nós que introduzimos esse método [científico]; ele se introduziu sozinho, e o movimento continuaria, mesmo que se quisesse eliminá-lo. Apenas constatamos o que acontece em nossas letras modernas. A personagem já não é uma abstração psicológica, eis o que todo mundo pode ver. A personagem se tornou um produto do ar e do solo, como a planta; é a concepção científica. ${ }^{21}$
}

A experimentação orienta os preceitos contidos nos ensaios críticos mencionados de Zola, visando inserir no romance um tom participativo nos problemas do tempo, com base em noções cientificistas. Sob esta ótica, o romance deveria mostrar a relação dos fenômenos sociais com seus determinismos, conforme leis e posteriores reformas sociais.

\footnotetext{
Zola, apesar de seu pessimismo em relação ao presente, é otimista em um futuro guiado pela ciência. As ciências sociais, para ele como para Comte, tinham um aspecto reformador, e deveriam levar ao aperfeiçoamento das condições externas da vida humana. A literatura deveria colaborar nesse processo, mostrando os problemas sociais para correção, por conta de uma atuação política sobre eles. O naturalista, então, tem
}

a "vida" em geral, mas a vida social em particular, ou seja, aquela província da realidade que se tornou especialmente importante para essa geração. HAUSER, Arnold. História Social da Arte e da Literatura. São Paulo: Martins Fontes, 1982, p. 749.

$20 \quad$ CARONI, Ítalo. A Utopia Naturalista. In: ZOLA, op. cit., 1995, p. 10.

21 ZOLA, op. cit., 1995, p. 40. 
como princípio esse viés reformador, visando a melhoria das condições sociais que geraram 0 aspecto degradante demonstrado pelo que Zola vai chamar de experiência. ${ }^{22}$ (grifo nosso)

A coexistência de ideários liberais e uma arte profundamente negativa pode representar um paradoxo aos escritores realistas. A raiz comum dessas direções é a posição incômoda do intelectual face à sociedade sob constantes transformações pela industrialização. É neste contexto que os autores agrediam o status quo na vida pública, como o fez destacadamente Émile Zola por meio de seus romances e artigos. Em Thérèse Raquin, podemos perceber a singularidade e a importância de Zola quando o mesmo descreve seus objetivos:

\begin{abstract}
Eu quis estudar temperamentos e não caracteres. Escolhi personagens soberanamente dominadas pelos nervos e pelo sangue, desprovidas de livre-arbítrio, arrastadas a cada ato de sua vida pelas fatalidades da própria carne. [...] Começa-se a compreender (espero-o) que meu objetivo foi acima de tudo um objetivo científico. [...] Fiz simplesmente em dois corpos vivos o trabalho analítico que os cirurgiões fazem em cadáveres (Prefácio à $2^{\mathrm{a}}$ ed. de Thérèse Raquin, 1868). ${ }^{23}$ (grifo nosso)
\end{abstract}

A estética naturalista focava o lado patológico dos indivíduos nas piores condições possíveis. $O$ detalhamento cauteloso das cenas são verdadeiros retratos de aspectos negativos do homem em sociedade. A abertura ao sexo, à miséria e à degradação humana são temas recorrentes nas observações experimentais como se fossem análises de um laboratório social, da forma pela qual os escritores acreditavam fazer. O homem é apresentado como um animal degenerado pela linguagem objetiva, simplificada e comum de fácil acesso e aproximação às pessoas, semelhantemente aos textos informativos.

O homem é reduzido a praticamente uma máquina de reações mecânicas, determinadas pelo meio, pela hereditariedade e pelo momento histórico. $O$ adultério, a valorização do presente e da razão ou a desmistificação das personagens nas suas formas mais horrendas, como retratos da sociedade, são alguns dos pontos em que o realismo naturalista se contrasta com o romantismo clássico.

Essa degradação é atribuída pelo meio em que vivem [as personagens] e por elementos hereditários, mas o movimento histórico conflitante que os determina a viver nesse meio acaba latente. Isso não quer dizer que Zola é um defensor do sistema capitalista, ao contrário; em seus escritos a atenção para a resolução dos problemas sociais, sua simpatia pelas classes mais baixas era evidente. A questão vai mais além:

$\begin{array}{ll}22 & \text { SILVA, op. cit., 2009, p. } 10 . \\ 23 & \text { ZOLA, } 1868 \text { apud BOSI, op. cit., 1976, p. } 169 .\end{array}$


Zola é filho de seu tempo, e sua concepção de mundo caminhava junto com 0 desenvolvimento científico da época. ${ }^{24}$ (grifo nosso)

A pretensa objetividade e a impassibilidade do narrador naturalista está intimamente ligada à posição do cientista em relação ao seu objeto de estudo. Este rigor metodológico evidencia a preocupação de manter-se a par da verdade no romance; preocupação esta realizada nas descrições. A descrição funciona como um elemento de análise científica. Zola afirma que não cabe ao romancista naturalista tirar conclusões de sua obra, visto que a experiência conclui por si.

[...] já não descrevemos por descrever, por um capricho e um prazer de retóricos. Achamos que o homem não pode ser separado de seu meio, que ele é completado por sua roupa, por sua casa, por sua cidade, por sua província; e, dessa forma, não notaremos um único fenômeno de seu cérebro ou de seu coração sem procurar as causas ou a consequência no meio. Daí o que se chama nossas eternas descrições. ${ }^{25}$

O naturalismo de Zola pode ser definido como um realismo descritivo, devido à posição fundamental que a descrição ocupa em sua obra. Outra característica importante do discurso realista-naturalista é a legibilidade, isto é, o mecanismo por meio do qual um enunciado se torna eficaz e consegue transmitir uma informação.

Nesse ponto, cabe ao escritor naturalista, portanto, adotar um estilo rudimentar e uma descrição tão fiel quanto o possível. A esses elementos se une um outro, referente à narrativa impessoal feita na terceira pessoa, em que ao eliminar do âmbito da enunciação qualquer vestígio de um narrador, instaura-se uma espécie de legitimidade narrativa.

Entre as principais obras de Émile Zola, na coletânea Les Rougon-Macquart, temos Le Ventre de Paris (1873), La Terre (1887), Nana (1880) e Germinal (1885). A Taverna (1876) e Nana26 apresentam uma atmosfera de degeneração; a partir de Germinal, a descrição experimental ganha contornos ainda mais fortes pela denúncia da opressão social e da paralisação moral da humanidade. Essa obra consagrou o autor como um dos maiores literatos de todos os tempos.

$24 \quad$ SILVA, op. cit., 2009, p. 41.

25 ZOLA, op. cit., 1995, p. 43. Para Zola, "um experimentador não tem que concluir, porque, justamente, a experiência conclui por ele. Cem vezes, se necessário, ele repetirá a experiência diante do público, a explicará, mas não terá que indignar-se, nem aprovar pessoalmente; tal é a verdade, tal é o mecanismo dos fenômenos; compete à sociedade continuar produzindo ou não este fenômeno, conforme seu resultado seja útil ou perigoso". ZOLA, op. cit., 1982, p. 53.

$26 \quad$ Para conceber Nana, Zola realizou uma profunda investigação do submundo parisiense; conversou com prostitutas, anotou seus hábitos, costumes e atitudes com clientes, percorreu casas noturnas e teatros, colheu depoimentos de gigolôs. Zola construiu um verdadeiro e amplo dossiê sobre a prostituição na capital francesa. 
Dentre outros livros podemos destacar La Bête Humaine (1890), no qual o autor expõe uma dura crítica ao regime político francês. A locomotiva enlouquecida que aguarda um final trágico nesta história seria uma representação da forma pela qual o Segundo Império francês estava sendo conduzido desvairadamente para a guerra franco-prussiana.

O ciclo dos Rougon-Macquart havia contado a história de um regime que não existia mais. Zola tinha 53 anos quando terminou o conjunto das obras. Havia escrito 20 romances, em 31 volumes, com 1200 personagens. Podia dar-se ao luxo de descansar, porém não queria esse luxo. O projeto da próxima obra já estava pronto: a posterior série Les Trois Villes (Lourdes - 1894, Rome - 1896 e Paris - 1898) abriria as agitações das cidades modernas. Quando este último romance apareceu, Zola foi envolvido pelo turbilhão do Caso Dreyfus.

Neste caso, Émile Zola demonstrou elevado engajamento político. Seu trabalho de maior repercussão certamente foi a carta aberta intitulada J'Accuse, destinada ao então presidente francês Félix Faure. Publicada na primeira página do jornal L'Aurore ${ }^{27}$ em 13 de janeiro de 1898, a carta acusava o governo francês de anti-semitismo por julgar e condenar o capitão Alfred Dreyfus, precipitadamente, por traição 28 .

27 L'Aurore foi um jornal republicano francês fundado em 1897, por Ernest Vaugan. A Biblioteca Nacional da França disponibiliza suas versões em formato digital no endereço <http://gallica.bnf.fr/ark:/12148/cb32706846t/date>. Acesso em 17 jan. 2010.

$28 \quad 0$ célebre processo sofrido pelo capitão Dreyfus representou um dos maiores erros judiciais da história contemporânea. A perseguição ao oficial começou em 1894, quando uma encarregada de limpeza na embaixada alemã em Paris, descobriu uma carta no cesto de lixo do militar alemão tenente-coronel Schwarzkoppen. 0 achado caiu nas mãos do serviço secreto francês, que concluiu ser o escrito a prova da existência de um traidor no corpo militar. Um bode expiatório fez-se necessário: a investigação chegou ao nome de Alfred Dreyfus, que foi submetido a uma prova caligráfica, detido e conduzido ao conselho de guerra. O capitão foi acusado de traição, condenado e enviado para Ilha do Diabo na Guiana Francesa para cumprir prisão perpétua. Em 1896, o tenente-coronel George Picquart, ao rever o caso, concluiu que o verdadeiro culpado era o major Charles-Ferdinand Walsin Esterhazy. O impasse chegou aos jornais e em pouco tempo muitos intelectuais do país se demonstraram solidários ao Caso Dreyfus. Émile Zola partiu em ampla defesa do acusado denunciando os culpados pela farsa, utilizando seu principal meio de mobilização pública: a imprensa escrita. A polêmica agrupou os franceses em duas frentes de batalha: os dreyfusards e os anti-dreyfusards. Somente em 1906 ocorreu uma revisão do processo, contudo Zola não pode presenciar a declaração de inocência e a reincorporação de Dreyfus ao exército francês, uma vez que o escritor havia falecido em 1902. A carta intitulada J'Accuse está disponível em <http://gallica.bnf.fr/ark:/12148/bpt6k701453s.pleinepage>. Acesso em 17 jan. 2010. 


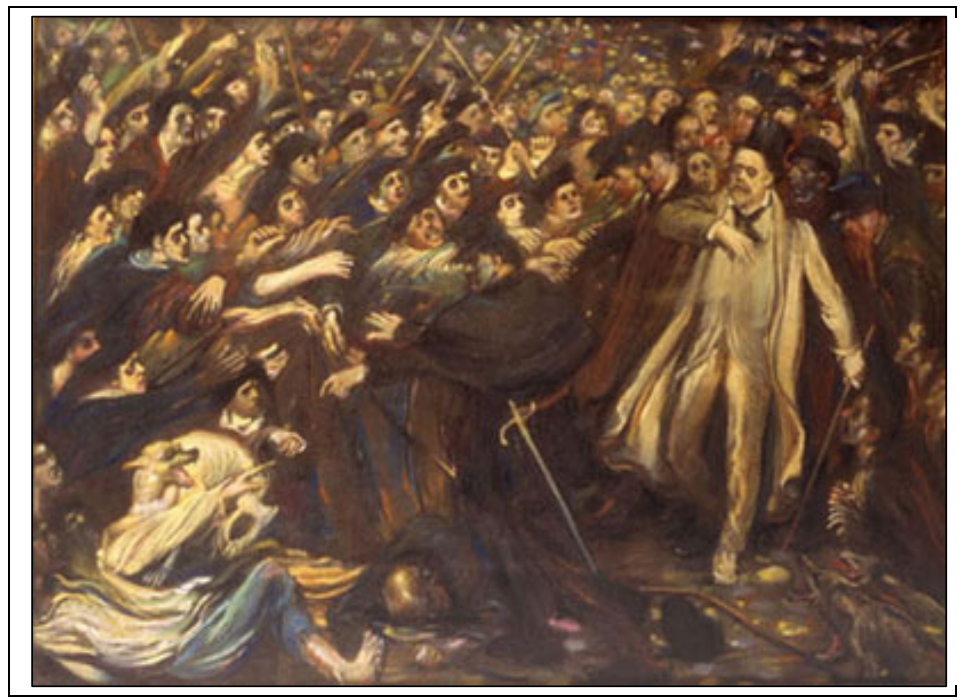

Figura 2. Zola Insultado, por Henri Degroux. 1898. Óleo sobre tela. ${ }^{29}$

Por sua manifestação e posicionamento no caso, Zola foi julgado e condenado a um ano de prisão; exilou-se em Londres e regressou à França após 11 meses. Veio a falecer em 29 de setembro de 1902, na cidade de Paris. Não se sabe a causa exata da morte. As análises indicaram possível inalação em quantidade letal de monóxido de carbono, porém alguns consideram a hipótese de assassinato devido seu posicionamento ao longo do Caso Dreyfus.

De acordo com Mitterand, três teses se contrapuseram a esse respeito: a da investigação oficial, que concluiu por acidente; a de uma investigação particular, datada de 1952, apoiada em testemunhos indiretos sobre a hipótese de homicídio; e outra, do comissário Marcel Leclère, inclinada pela hipótese de uma morte involuntária resultante de erro. ${ }^{30}$ Sua vida se concluiria após uma defesa ferrenha do capitão Dreyfus.

Até hoje não se esclareceu completamente se a prisão e condenação de Dreyfus foi
simplesmente um erro judicial que, por acaso, deu lugar a uma conflagração política, ou
se o Estado-Maior deliberadamente forjou o bordereau ${ }^{31}$ e usou-o como embuste para o
fim expresso de finalmente estigmatizar um judeu como traidor. Em apoio dessa última
hipótese, há o fato de que Dreyfus foi o primeiro judeu a galgar um posto no Estado-Maior

29 Degroux retrata o ódio das massas durante a saída do escritor do tribunal. Fonte: Musée Émile Zola - Médan. Disponível em <http://www.amis-arts.com/poetes/zola/2_dreyfus/Zola_sortie.jpg>. Acesso em 12 mai. 2010.

$30 \quad$ MITTERAND, op. cit., 2006, p. 1.

31 Le bordereau foi a forma pela qual a imprensa francesa designou o documento descoberto pela encarregada de limpeza na embaixada alemã. 
e, nas condições da época, isso podia ter causado não apenas aborrecimento, mas verdadeira fúria e consternação. ${ }^{32}$

Os correspondentes brasileiros em Paris foram importantes intermediários no anúncio das publicações, polêmicas e notícias envolvendo Émile Zola, o que contribuiu para divulgação de seu nome neste país. A crítica brasileira, como indica Eduardo Silva, oscilou entre dois pólos: de um lado a grande admiração pelo talento do escritor, de outro, profundas recriminações de caráter moral. Todavia, é inegável o peso que Zola representou na literatura ocidental oitocentista. ${ }^{33}$ Como indício de admiração por sua obra e pela sua dedicação ao Caso Dreyfus, Tobias Monteiro, em entrevista com o "Sr. Zola" assim se manifestou sobre o escritor, no Jornal do Commercio em 1898:

\begin{abstract}
Inspirou-se no amor da justiça e da verdade. Está certo de inocência do acusado, e por isso dispôs-se a promover a revisão do processo, para os juízes se convencerem da existência do erro judiciário. [...] Nenhum, porém se elevara quanto ele desde 0 dia do retumbante libelo "J'accuse", que pôs ante o pretório da consciência universal todos os culpados da horrível perseguição de um inocente, escolhido para pasto de ódios de raça. As suas faculdades criadoras, os seus recursos poderosos de linguagem faziam desprender dos seus escritos uma irradiação de verdade, que iluminava todas as cenas daquele drama abominável e permitia caminhar com firmeza, na esperança do desfecho triunfal da justiça. ${ }^{34}$
\end{abstract}

Ainda na virada dos séculos, Zola começou um novo ciclo (a série Les Quatre Evangiles Fécondité, Travail, Vérité, Justice), porém morreu antes de terminar o quarto livro. Voltou-se para a utopia da marcha para a fraternidade e felicidade humanas, ao passo que desapareceu antes de assistir ao "retorno da barbárie" marcado pela Grande Guerra Mundial que viria eclodir. Seis anos após o falecimento, os restos mortais de Émile Zola foram levados ao Panthéon, espaço onde estão sepultadas diversas figuras de renome como Victor Hugo, Rousseau, Voltaire e outros. ${ }^{35}$

\title{
Anexo: Obras Publicadas 36
}

\section{Romances}

As Costureirinhas de Provença - Les Grisettes de Provence (1859)

32 ARENDT, Hannah. O Caso Dreyfus. In: As Origens do Totalitarismo. Tradução de Roberto Raposo. São Paulo: Companhia das Letras, 1989, p. 127.

$33 \quad$ SILVA, op. cit., 1999, p. 356.

34 MONTEIRO, Tobias. Entrevista com o Sr. Zola, Jornal do Commercio. Rio de Janeiro: 1898. In: SILVA, op. cit., 1999 , p. 349.

35 Victor-Marie Hugo (1802-1885) foi um romancista francês famoso por diversas obras entre elas: Les Misérables (1862) e Notre-Dame de Paris (1831). François-Marie Arouet, pseudônimo Voltaire (1694-1778) foi um escritor e filósofo francês conhecido por sua defesa das liberdades civil, religiosa e de livre-comércio. Jean-Jacques Rousseau (1712-1778) foi um filósofo e teórico político suíço de destaque na tradição iluminista e no romantismo.

36 É importante salientar que grande parte de sua obra ficcional e crítica foi publicada anteriormente em jornal. 
Contos à Ninon - Contes à Ninon (1864)

- A confissão de Claude - La confession de Claude (nov 1865)

$>$ O juramento de uma morte - Le vœu d'une morte (nov 1866)

$>$ Esboços Parisienses - Esquisses Parisiennes (1866)

$>$ Os mistérios de Marseille - Les mystères de Marseille (1867)

- Folhetim: Le Messager de Provence

- Tomo I de 2 mar a 14 de maio

- Tomo ll de 23 maio a 29 de ago

- Tomo III de 19 de set a 1 fev de 1868

- Em volume, junho e outubro

Thérèse Raquin (dez 1867)

Madeleine Férat (1868)

- Folhetim: L'événement illustré de 2 set a 20 out

- Livro: dezembro

Novos contos à Ninon - Nouveaux contes à Ninon (1874)

- As noites de Médan - Les soirées de Médan (1880)

> Madame Sourdis (1880)

$>$ O capitão Burle - Le capitaine Burle (1882)

$>$ Naïs Micoulin (1884)

\section{A saga dos Rougon-Macquart}

A fortuna dos Rougon - La fortune des Rougon (1870)

- Folhetim: Le Siècle, 28 jun (interrompido)

- 10 ago, continuação

- Livro: outubro 1871

- Reedição em dez 1872

$>$ O regabofe - La Curée (1871)

- Folhetim: La Cloche de 28 set a 5 nov

- Interrompida sob intervenção

- Reedição em jan 1872

$>O$ ventre de Paris - Le ventre de Paris (1873)

- Folhetim: L'État de 12 jan a 17 mar

- Livro: maio

> A conquista de Plassans - La conquête de Plassans (1874)

- Folhetim: Le Siècle de 24 fev a 25 abr

- Livro: junho

O crime do padre Mouret - La faute de l'abbé Mouret (1875)

- Folhetim: Le Messager de l'Europe, fev e mar

- Livro: abril

O senhor ministro - Son excellence Eugène Rougon (1876)

- Folhetim: Le Siècle de 25 jan a 11 mar

- Livro: fevereiro

A taberna - L'assommoir (1876)

- Folhetim: Le Bien Public de 7 jul a 7 jan 1877

- Livro: março 
Uma página de amor - Une page d'amour (1878)

- Folhetim: Le Bien Public de 11 dez a 4 abr

- Livro : abril

$>$ Nana (1879)

- Folhetim: Le Voltaire de 16 out a 5 fev

- Livro: março

- A roupa suja - Pot-Bouille (1882)

- Folhetim: Le Gaulois 23 jan a 14 abr

- Livro: abril

O paraíso das damas - Au bonheur des dames (1883)

- Folhetim: Gil Blas 17 dez a 1 mar 1882

- Livro: março

A alegria de viver - La joie de vivre (1884)

- Folhetim: Gil Blas 28 nov a 3 fev 1883

- Livro: março

Germinal (1885)

- Folhetim: Gil Blas 26 nov a 25 fev 1884

- Livro: março

A obra - L'ouvre (1886)

- Folhetim: Gil Blas 23 dez a 27 mar

- Livro: março

A Terra - La Terre (1887)

- Folhetim: Gil Blas de 29 mai a 16 set

- Livro: novembro

O sonho - Le rêve (1888)

- Folhetim: Revue lllustré 1 abr a 15 out

- Livro: outubro

- A besta humana - La bête humaine (1890)

- Folhetim: La Vie Populaire 14 nov 1889 a 2 mar

- Livro: março

O dinheiro - L'argent (1891)

- Folhetim: Gil Blas 30 nov a 4 mar 1890

- Livro: março

> A derrocada - La débâcle (1892)

- Folhetim: La Vie Populaire 21 fev a 21 jul

- Livro: junho

O doutor Pascal - Le docteur Pascal (1893)

- Folhetim: La Revue Hebdomadaire 18 mar a 17 jun

- Livro: junho

\section{Série Três Cidades}

Londres - Lourdes (ago 1894)

Roma - Rome (maio 1896)

$>$ Paris (mar 1898)

\section{Série Quatro Evangelhos}


Fertilidade - Fécondité (out 1899)

$>$ Trabalho - Travail (jul 1901)

> Verdade - Vérité (fev 1903 - publicado postumamente)

$>$ Justice (não terminado)

\section{Peças de Teatro}

Thérèse Raquin (1873)

$>$ Os herdeiros Rabourdin - Les héritiers Rabourdin (1874)

$>$ O botão de rosa - Le bouton de rose (1878)

$>$ Renée (1887)

$>$ Poemas líricos - Poèmes lyriques

\section{Obras Críticas}

> Confidências de um curioso - Confidences d'une curieuse (1865)

$>$ Meus ódios - Mes haines (1866)

$>$ Chroniques (1868-1870)

> A República em marcha - La République em marche (1868-1872)

$>$ Letras Parisienses - Lettres Parisiennes (1872)

> Estudos sobre a França contemporânea - Études sur la France contemporaine (18751878)

> O romance experimental - Le roman expérimental (1880)

$>$ Nossos dramáticos autores - Nos auteurs dramatiques (1881)

$>$ Os romances naturalistas - Les romanciers naturalistes (1881)

$>$ O naturalismo no teatro - Le naturalisme au théâtre (1881)

$>$ Documentos literários - Documents littéraires (1881)

$>$ Nossos autores dramáticos - Nos auteurs dramatiques (1881)

> Uma campanha - Une campagne (1882)

$>$ Nova campanha - Nouvelle campagne (1896)

> Impressões de audiências: páginas do exílio - Impressions d'audiences: pages d'exil (1898)

> A verdade em marcha - La vérité en marche (1901)

\section{Poesia}

$>$ Messidor (1898)

> O furacão - L'ouragan (1901)

\section{Referências Bibliográficas}

1. ARENDT, Hannah. O Caso Dreyfus. In: As Origens do Totalitarismo. Tradução de Roberto Raposo. São Paulo: Companhia das Letras, 1989.

2. BOSI, Alfredo. História concisa da literatura brasileira. São Paulo: Cultrix, 1976.

3. CARA, Salete de Almeida. Marx, Zola e a Prosa Realista. São Paulo: Ateliê Editorial, 2009.

4. CARPEAUX, Otto Maria. História da literatura ocidental. Rio de Janeiro: O Cruzeiro, 1966. 
5. MITTERAND, Henri. Émile Zola - entre a genialidade e a justiça. In: Históriaviva, ed. 35, set. 2006. Disponivel em <http://www2.uol.com.br/historiaviva/reportagens/emile_zola_entre_a_genialidade_e_a_justica.html $>$. Acesso em 31 out. 2009.

6. Zola à Anzin: les mineurs de Germinal. In: Travailler, 2002/1, n 7, p. 37-51. Disponível em <http://www.cairn.info/revue-travailler-2002-1-page-37.htm>. Acesso em 13 jul. 2010.

$7 . \quad$ Zola et naturalisme. Paris: P.U.F. (Collection Que sans-je?), 1986.

8. MONTEIRO, Tobias. Entrevista com o Sr. Zola, Jornal do Commercio. Rio de Janeiro: 1898.

9. RODRIGUES, Marília Mezzomo. "Sou um historiador e não um fornecedor de imundícies!" medicina experimental e hereditariedade no naturalismo de Émile Zola. In: Revista de História Regional, n. 14 (2), Inverno, 2009, p. 29-52.

10. SILVA, Eduardo César Ferreira da. A obra de Émile Zola no Brasil: notas para um estudo de recepção crítica. Dissertação (Mestrado em Literatura), Universidade Federal de Santa Catarina, 1999.

11. SILVA, Júlio Cezar Bastoni da. O cortiço e os limites do romance experimental. Monografia (Graduação) - Curso de Letras, Universidade Federal de São Carlos, 2009.

12. ZOLA, Émile. Do romance. Tradução de Plínio Augusto Coelho. São Paulo: Edusp, 1995.

13. - Germinal. Paris: Librarie Illustrée, 1885. Disponivel em $<$ http://gallica.bnf.fr/ark:/12148/bpt6k5493777b.image.r=Germinal.langPT.f9.pagination>. Bibliothèque Nationale de France. Acesso em 10 out. 2009.

14. Germinal. Tradução de Francisco Bittencourt. São Paulo: Martin Claret, 2007.

15. J'Accuse. Documento eletrônico (em francês). Disponível em $<$ http://www.dominiopublico.gov.br/download/texto/aa000123.pdf>. Acesso em 17 jul. 2010.

16. O O romance experimental e o naturalismo no teatro. São Paulo: Perspectiva, 1982.

17. ZOLA, Émile; BARBOSA, Rui. Eu Acuso! O Processo do Capitão Dreyfus. Organização e tradução de Ricardo Lísias. São Paulo: Hedra, 2007.

\section{Filmografia}

1. GERMINAL. Direção: Claude Berri. Bélgica, França e Itália: AMLF, 1993. 1 filme (160 min), son., color.

2. THE LIFE OF ÉMILE ZOLA. Direção: William Dieterle. Estados Unidos: Warner Bros., 1937. 1 filme (116 min), son., preto e branco.

Artigo recebido em: 15/03/2011 Aprovado em: 15/04/2011 